\title{
Imaging Infrared Spectrometer onboard Chandrayaan-2 Orbiter
}

\author{
Arup Roy Chowdhury*, Arup Banerjee, S. R. Joshi, Moumita Dutta, \\ Ankush Kumar, Satadru Bhattacharya, Amitabh, Sami Ur Rehman, Sunil Bhati, \\ J. C. Karelia, Amiya Biswas, Anish R. Saxena, Satish Sharma, \\ Sandip R. Somani, H. V. Bhagat, Jitendra Sharma, D. N. Ghonia, \\ B. B. Bokarwadia and Ajay Parasar
}

Space Applications Centre, Indian Space Research Organisation, Ahmedabad 380 015, India

Imaging Infrared Spectrometer (IIRS) is an imaging hyperspectral instrument for mineralogy of the lunar surface (including the hydroxyl signature). IIRS operates in the $0.8-5 \mu \mathrm{m}$ spectral range with about 250 contiguous bands. It has $80 \mathrm{~m}$ ground sampling distance and $20 \mathrm{~km}$ swath at nadir from $100 \mathrm{~km}$ orbit altitude. Optical design is based on fore-optics and Offner (convex multi-blazed grating)-type spectrometer. Focal plane array is $\mathrm{HgCdTe}$ (mercury-cadmium-telluride)based actively cooled to $90 \mathrm{~K}$, having $500 \times 256$ pixels format with $30 \mu \mathrm{m}$ pixel size. Electronics comprises proximity, logic and control, power supply and cooler drive electronics. Mechanical system is realized to house various subsystems, namely optics, detector, electronics and thermal components meeting the structural, opto-mechanical thermal component and alignment requirements. Thermal system is designed such that the instrument is cooled and maintained at fixed temperature to reduce and control instrument background. Aluminum-based mirror, grating and housing are developed to maintain structural as well as opto-mechanical and thermal requirements. This article presents IIRS realization and spectroradoimetric performance.

Keywords: Hyperspectral imaging, infrared spectrometer, Moon, orbiter.

IMAGING Infrared Spectrometer (IIRS) ${ }^{1}$ is an advanced version of the Hyper Spectral Imager (HySI) ${ }^{2}$, Moon Mineralogy Mapper $\left(\mathrm{M}^{3}\right)$ (ref. 3) and near IR spectrometer (SIR-2) $)^{4}$ flown on Chandrayaan-1. The spectral range of this instrument is extended up to $5.0 \mu \mathrm{m}$. The ground sampling would be $80 \mathrm{~m}$ with swath coverage of $20 \mathrm{~km}$. IIRS is a grating-based dispersive instrument, which would provide instantaneous spectra of the lunar surface. The reflected and emitted radiation from the lunar surface, in the spectral range $0.8-5 \mu \mathrm{m}$, would

\footnotetext{
*For correspondence. (e-mail: arc@sac.isro.gov.in)
}

be mapped by this instrument. Instruments onboard Chandrayaan-1 have detected and mapped the hydroxyl signature which is indicative of the presence of $\mathrm{OH} / \mathrm{H}_{2} \mathrm{O}$ on the lunar surface. The scientific community is looking for more quantitative analyses of the lunar surface using high-resolution (spatial and spectral) imaging instrument with an extended spectral range. IIRS imagery in $2-5 \mu \mathrm{m}$ spectral region would confirm and quantify findings of instruments onboard Chandrayaan-1 with greater certainty. Imaging in the $4-5 \mu \mathrm{m}$ spectral region would be used to independently assess thermal emissions from the lunar surface. This would be helpful in correcting the thermal component of the total radiation in $2-3.5 \mu \mathrm{m}$ region. The spectral region of 3.5-5 $\mu \mathrm{m}$ would be used to understand the thermal properties of the lunar surface. This article highlights system design and spectroradiometric performance of the flight-grade instrument.

\section{Science and observation scheme}

Remote detection of water and/or hydroxyl signatures on the lunar surface has recently acquired importance as it provides important clues to understanding the exogenous and endogenous sources and formation mechanisms that have led to their detection on the surface. In this context, Chandrayaan-1's $\mathrm{M}^{3}$ has contributed immensely towards the detection of widely distributed hydration signatures across the Moon and at places, localized and more isolated occurrences have also been noticed ${ }^{5-12}$. However, due to the limited spectral coverage of $\mathrm{M}^{3}$ up to $3.0 \mu \mathrm{m}$, the exact nature of the observed hydration signatures cannot be ascertained.

Thus, in order to understand the exact nature of the observed lunar hydration feature, IIRS, onboard Chandrayaan-2, has been designed to cover an extended spectral range up to $5.0 \mu \mathrm{m}$ that will map the lunar surface at a spatial resolution of $\sim 80 \mathrm{~m}$ in about $\sim 250$ spectrally contiguous channels.

The primary objective of IIRS is to detect and map the lunar surface composition and volatiles to understand the 
origin and evolution of the Moon in a geologic context. Even though almost $95 \%$ of the lunar surface has been already mapped by Chandrayaan- $1 \mathrm{M}^{3}$, IIRS having a relatively higher spatial and spectral resolution and an extended spectral range beyond $3 \mu \mathrm{m}$, will reassess the chemical make-up of the lunar crust and provide a global inventory of the lunar hydration. Specific science objectives have been identified to map the lunar mineral and water resources. These include global mineralogical and $\mathrm{OH} / \mathrm{H}_{2} \mathrm{O} / \mathrm{H}_{2} \mathrm{O}$-ice mapping of the lunar surface in the spectral range $\sim 0.8-5.0 \mu \mathrm{m}$ for the first time. The spectral range of 2.5-3.5 $\mu \mathrm{m}$ would be beneficial in characterizing the hydration feature, i.e., whether $\mathrm{OH} / \mathrm{H}_{2} \mathrm{O} / \mathrm{H}_{2} \mathrm{O}$-ice is present in the lunar regolith and within the bedrock exposures of nominally anhydrous minerals at some crater central peaks and basin inner rings. IIRS will also help in understanding the sources and processes (endogenic and/or exogenic) responsible for the presence of $\mathrm{OH} /$ $\mathrm{H}_{2} \mathrm{O} / \mathrm{H}_{2} \mathrm{O}$-ice on the lunar surface.

Apart from this, the high spatial resolution of IIRS would be handy in detecting and mapping the composition of very young (less than 100 million years) volcanic features on the Moon, which in turn will help in getting insights into the petrogenesis of these volcanic rocks. Spectral compositional analysis of lunar pyroclastic deposits and their petrological implications would be another important aspect that will be studied using Chandrayaan-2 IIRS data. Based on the analysis of IIRS data over the lunar globe, more focused and targeted studies can be taken up for future scientific and exploration missions.

IIRS will be measuring radiation from the lunar surface at an altitude of $100 \mathrm{~km}$ on a polar circular orbit at a spatial resolution of $\sim 80 \mathrm{~m}$ and spectral resolution of $\sim 20$ $25 \mathrm{~nm}$ across the spectral range $0.8-5.0 \mu \mathrm{m}$ in about 250 spectrally contiguous bands. The diagnostic absorption features of major and minor lunar minerals will be detected primarily in the spectral range $\sim 0.8-2.5 \mu \mathrm{m}$, whereas $\sim 2.5-3.5 \mu \mathrm{m}$ spectral range will be dedicatedly used to map the presence of lunar $\mathrm{OH} / \mathrm{H}_{2} \mathrm{O} / \mathrm{H}_{2} \mathrm{O}$-ice features having fundamental absorptions around $3.0 \mu \mathrm{m}$. Spectral band parameters such as band depth, band centre, band area, continuum slope, etc. will be computed to characterize the lunar minerals and hydroxyl/water molecules. In-orbit calibration will be carried out by observing pre-defined sites and deep space. Figure 1 shows the reflectance spectra of major lunar rock-forming silicates and soil sample from Apollo return samples in the spectral range of $0.5-4.0 \mu \mathrm{m}$.

However, the measured reflected radiance will be contaminated by the contribution from lunar thermal emission beyond $2.0 \mu \mathrm{m}$. IIRS would be able to better discriminate between the reflected solar radiance and thermal emission from the lunar surface, which can obscure weaker absorptions arising due to the fundamental water absorptions.
IIRS will be nominally operated for $10 \mathrm{~min}$ in an imaging session. In specific cases, it will be operated for more time, e.g. $20 \mathrm{~min}$. It will observe predefined priority sites in the initial phase of operation. For different illumination conditions and reflective properties of the lunar

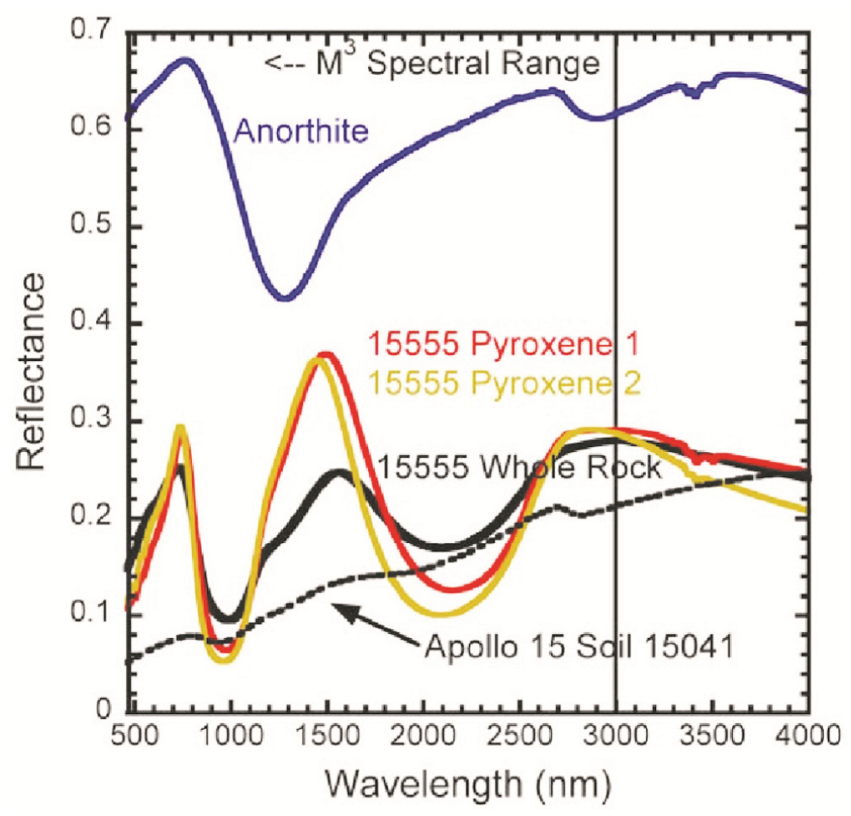

Figure 1. Reflectance spectra of particulate lunar soil, rock and minerals measured in Earth-based laboratory (RELAB) in the spectral range $\sim 0.5-4.0 \mu \mathrm{m}$ comparable with the IIRS spectral range (source: supporting on-line Material by Pieters et al. ${ }^{5}$ published in Science).

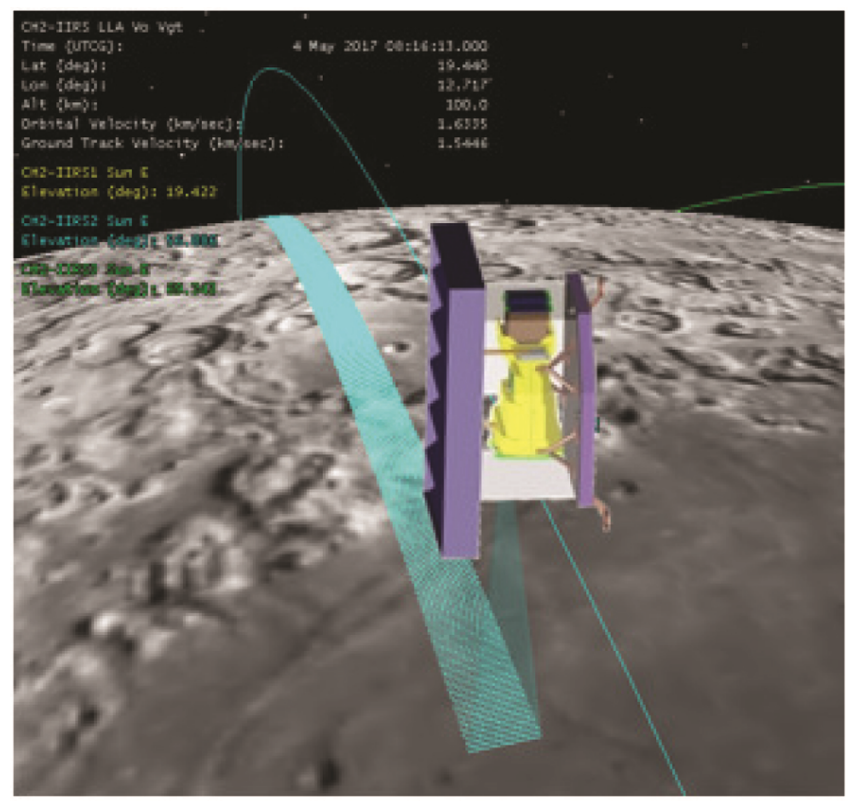

Figure 2. Typical nadir observation geometry of IIRS in the lunar orbit of $100 \mathrm{~km}$ altitude. 
surface (equatorial - polar regions, highland-mare regions), the signal will vary; the instrument has multiple exposure and gain settings for covering the range. Nominal operation of the IIRS is in the nadir-viewing geometry (Figure 2).

\section{System specifications}

The instrument (from $100 \mathrm{~km}$ altitude) would cover $20 \mathrm{~km}$ swath at $80 \mathrm{~m}$ ground sampling distance (GSD) with spectral resolution of about $20-25 \mathrm{~nm}$ in the wavelength range from 0.8 to $5 \mu \mathrm{m}$. Table 1 gives major specifications of the IIRS.

\section{System configurations}

Payload subsystems have been designed with the aim to meet performance at system level, taking into consideration the various design constraints such as available technologies, resources (permissible limits of mass, power and volume), timeline and budget (Figure $3 a$ ). Major subsystems are optical system, detector head assembly, payload electronics, mechanical and thermal control systems. Figure $3 b$ shows a mechanical model of the payload.

\section{Optical system}

The IIRS optics comprises two parts, namely fore-optics and spectrometer optics (Figure $4 a$ ). Table 2 provides parameters of the optical system. Considering the broad spectral range of $0.8-5 \mu \mathrm{m}$ and high system throughput requirement, all reflective (Figure $4 b$ ) optical configuration is selected. Fore-optics configuration is a threemirror anastigmat (TMA) to meet image quality, field curvature and telecentricity requirements. Fore-optics collects signal from target or scene and focuses it onto the slit, which passes a very narrow beam of light into the spectrometer optics. Spectrometer optics configuration is Offner-type (i.e. convex grating-based), which spectrally disperses and re-images again on to the focal plane with

Table 1. Major specifications of IIRS

\begin{tabular}{lc}
\hline Parameter & Values \\
\hline Platform altitude $(\mathrm{km})$ & 100 \\
Ground sampling distance $(\mathrm{m})$ at nadir & 80 \\
Swath $(\mathrm{km})$ at nadir & 20 \\
Spectral range $(\mu \mathrm{m})$ & $0.8-5$ \\
Spectral resolution (full width at half maximum, & $\sim 20-25$ \\
$\quad$ FWHM; nm) & \\
Noise equivalent differential radiance & $\leq 0.005$ \\
$\quad$ NEdR; $\left.\mathrm{mW} / \mathrm{cm}^{2} / \mathrm{sr} / \mu \mathrm{m}\right)$ & \\
No. of spectral bands & $\sim 250$ \\
Quantization $(\mathrm{bit})$ & 14 \\
\hline
\end{tabular}

different wavelengths and fields on different pixels of area array detector.

\section{Focal plane assembly}

Considering the broad spectral range of $0.8-5 \mu \mathrm{m}$, technology availability, operational and performance requirements, mercury-cadmium-telluride (MCT or $\mathrm{HgCdTe}$ ) is found to be superior compared to other detector alternatives. The detector array operation is with active cooling system to achieve performance requirements in terms of dark current and dark noise. The detector is maintained at $90 \mathrm{~K}$ and consumes about $500 \mathrm{~mW}$ power. The detector is housed in a vacuum dewar and attached to the tip of closed cycled helium (He)-based cooler. This arrangement permits (integrated detector dewar cooler assembly (IDDCA)) operation in ambient conditions. A rotary stirling cooler is chosen to meet the mission requirements with respect to mass, power, volume, life, shock, and vibration. A four-band cold filter (also called ordersorting-filter (OSF)) is mounted inside the dewar in close proximity to the detector, for dual purpose: (i) restrict the energy from unintended diffraction orders (due to grating-based configuration) and (ii) reduce instrument background flux. Figure $5 a$ and $b$ shows IDDCA crosssectional view and IIRS FPA respectively. Table 3 provides detector parameters.

\section{Payload electronics}

Payload electronics (PLE) comprises three packages, namely (i) PLE-21: proximity electronics - processing, command and control electronics; (ii) PLE-22: cooler drive electronics; and (iii) PLE-23: power supply electronics. Table 4 gives the payload electronics parameters. The proximity electronics generates precision bias, clock, control signals, digitizes video signals using 12-bit digitizer and performs data binning (spatial and frame, translated to 14 bit). Two gains and four exposure settings are available. The settings can be exercised through ground commanding. PLE also generates command and control signals necessary for payload operation. The cooler drive electronics provides necessary stimuli for cooler operation and maintains FPA temperature to within $100 \mathrm{mK}$ (from set temperature $\sim 90 \mathrm{~K}$ ) using a close loop control system.

The power supply electronics provides regulated power to each of the subsystems. Figure $6 a-d$ shows the block schematic of the payload electronics and electronic cards.

\section{Mechanical and thermal control system}

The mechanical system consists of fore-optics assembly, spectrometer optics assembly, detector head assembly, 
RESEARCH ARTICLES
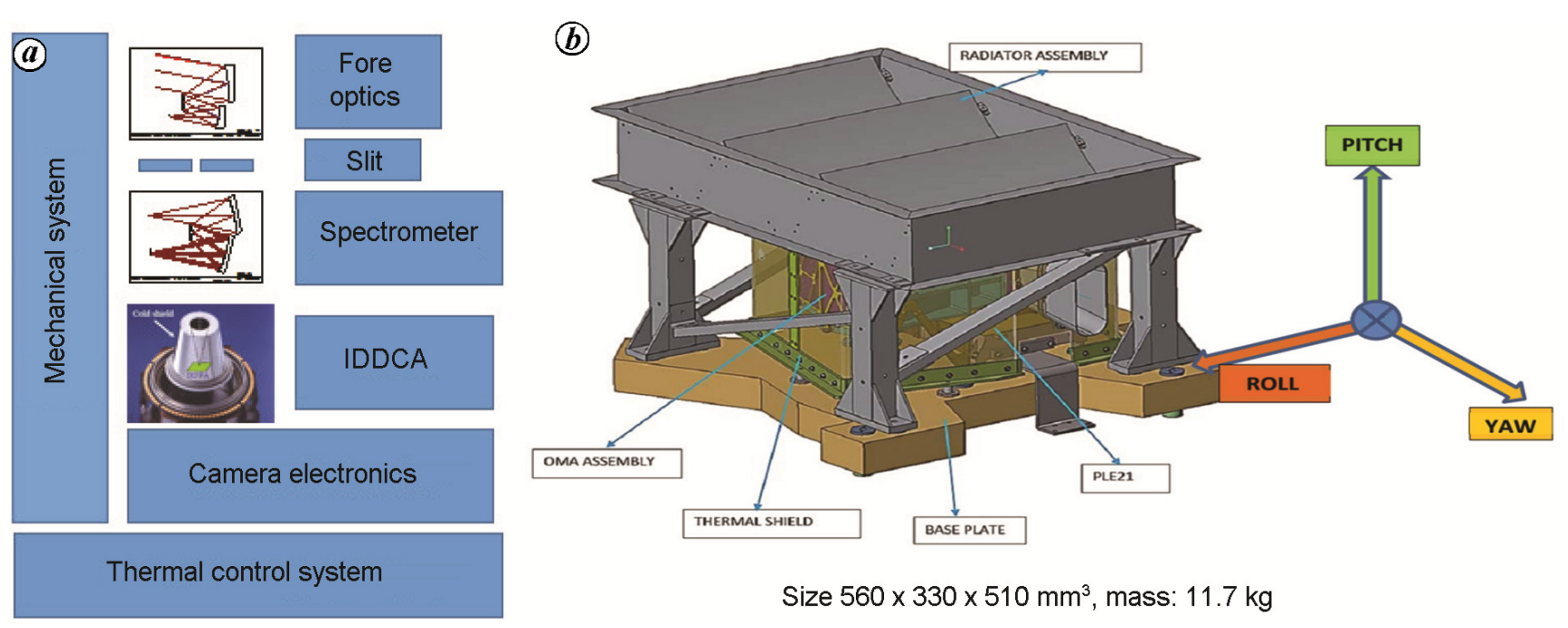

Figure 3. Payload configuration and mechanical model.

Table 2. Optical system parameters

\begin{tabular}{ll}
\hline Parameter & \multicolumn{1}{c}{ Values } \\
\hline Configuration & Fore-optics: TMA and spectrometer: Offner-type \\
Spectral range $(\mu \mathrm{m})$ & $0.8-5$ \\
Spectral sampling $(\mathrm{nm} /$ pixel) & 16.85 \\
IFOV (mrad) & 0.4 \\
Field-of-view (FOV; degrees) & \pm 5.7 \\
Effective focal length (EFL; mm) & 75 \\
f-number & 2.5 \\
Optical efficiency (OE) & Spectrally tuned and maximized in 2-3.5 $\mu \mathrm{m}$ spectral range \\
Optics MTF (@Nq 171 p/mm) & $>60$ \\
Smile & $<$ Pixel/10 \\
Keystone & $<$ Pixel/10 \\
Order sorting filter (OSF) & Four band-pass filters joined together. OSF is part of the \\
& focal plane array \\
\hline
\end{tabular}

Table 3. Detector parameters

\begin{tabular}{|c|c|}
\hline Parameter & Values \\
\hline Configuration & $\begin{array}{l}\text { Integrated detector dewar cooler assembly (IDDCA) with } \\
\text { order-sorting filter mounted inside the dewar and close to } \\
\text { focal plane assembly (FPA) or retina }\end{array}$ \\
\hline Material & Mercury-cadmium-telluride (MCT) \\
\hline Spectral range $(\mu \mathrm{m})$ & $0.8-5$ \\
\hline Pixel size $(\mu \mathrm{m})$ & 30 \\
\hline Detector format & $500($ spatial $) \times 256($ spectral $)$ \\
\hline Full well capacity (kiloelectron) & 500 (G1) and 2200 (G2) \\
\hline Quantum efficiency (QE) & Flat profile across the full spectral range \\
\hline Retina temperature $(\mathrm{K})$ & $\sim 90$ \\
\hline Power consumption & $\begin{array}{l}\sim 11.3 \mathrm{~W} \text { (cool down) } \\
\sim 7.9 \mathrm{~W} \text { (regulation) }\end{array}$ \\
\hline Cooler type & Rotary \\
\hline
\end{tabular}

electronics packages, radiator and base plate. The optics and detector module is known as electro-optical module (EOM). The mechanical system caters to structural, thermal and optical requirements to meet the overall system performance. Construction material is kept same for optics and structure in order to achieve athermalized nature of the instrument. This allows consistency of the optical performance at different temperatures. 
Table 4. Payload electronics parameters

\begin{tabular}{ll}
\hline Parameter & \multicolumn{1}{c}{ Values } \\
\hline Configuration & $\begin{array}{c}\text { Proximity electronics; processing, command and control electronics; } \\
\text { cooler drive electronics and power supply electronics }\end{array}$ \\
Onboard pixel binning & 2 (swath pixels) $\times 2$ (lines in along track) \\
& No spectral binning \\
Quantization (bit) & 14 (with $2 \times 2$ binning) (raw: 12 bit) \\
Exposures (ms) & E1: $1 \mathrm{~ms}$, E2: $3 \mathrm{~ms}$, E3: $10 \mathrm{~ms}$, E4: $21 \mathrm{~ms}$ \\
Gains & G1 and G2 \\
Telecommand & Payload ON/OFF, cooler ON/OFF and for gain and exposure \\
& selection \\
\hline
\end{tabular}
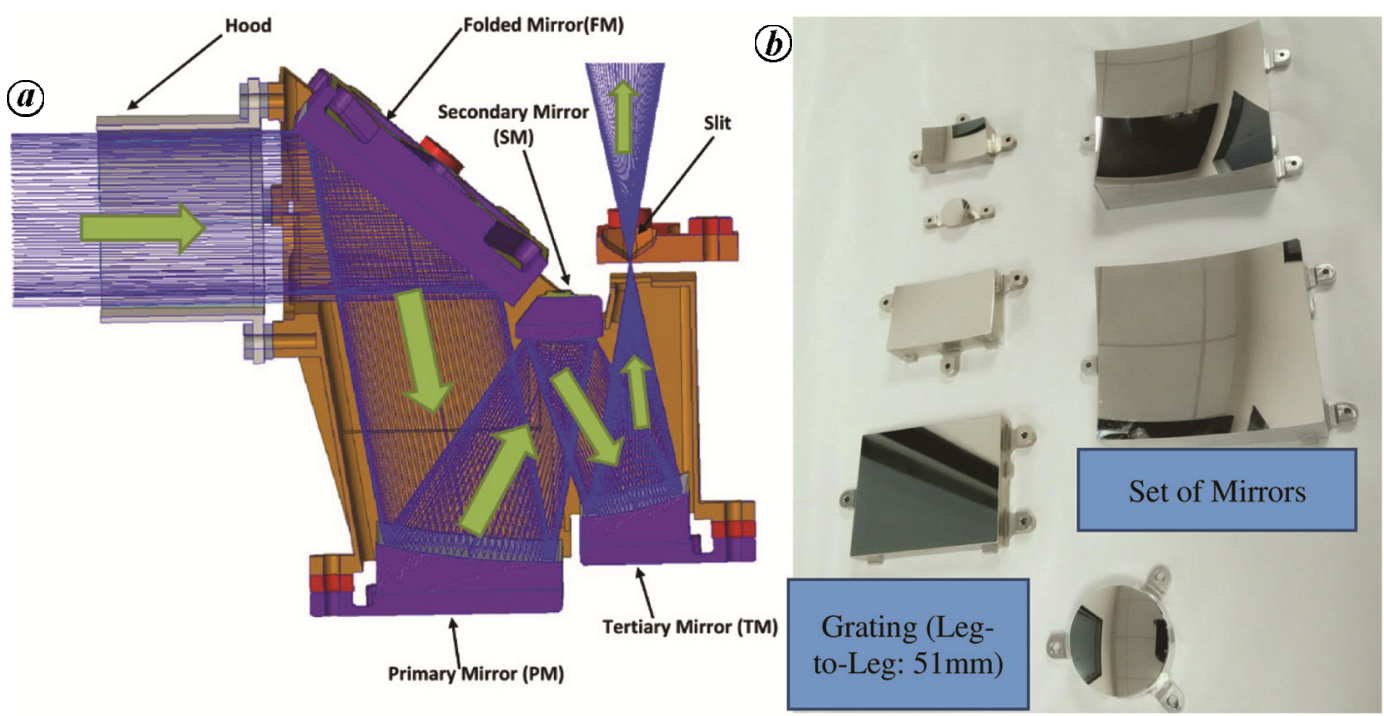

Figure 4. Optical configuration and optical elements.
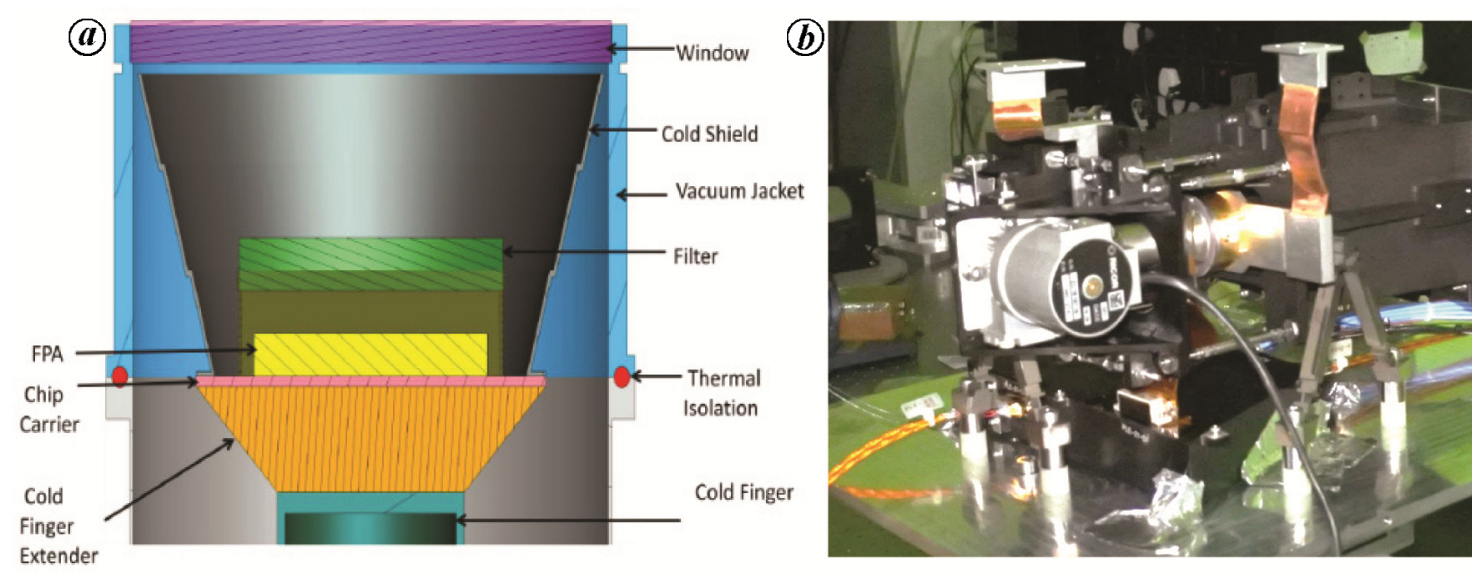

Figure 5. $\boldsymbol{a}$, Integrated detector Dewar cooler assembly cross-sectional view. $\boldsymbol{b}$, IIRS focal plane assembly.

Due to the relative motion of the Earth, Moon and Sun, solar illumination angle on spacecraft surface changes at about $1 \%$ day. Hence, primarily two extreme orbit conditions from thermal control point of view are: (i) noonmidnight: where the Sun vector is parallel to the spacecraft orbit plane and (ii) dawn-dusk: where the Sun vector is perpendicular to the spacecraft orbit plane.
The adopted thermal design makes use of both active and passive thermal control techniques. FPA is cooled using an active cooler. Heat from IDDCA and optics is removed using passive thermal control techniques augmented with the electrical heaters. Three-tier thermal isolation is provided: (i) Payload is thermally isolated from $\mathrm{S} / \mathrm{C}$ deck using low thermal conductive material; 

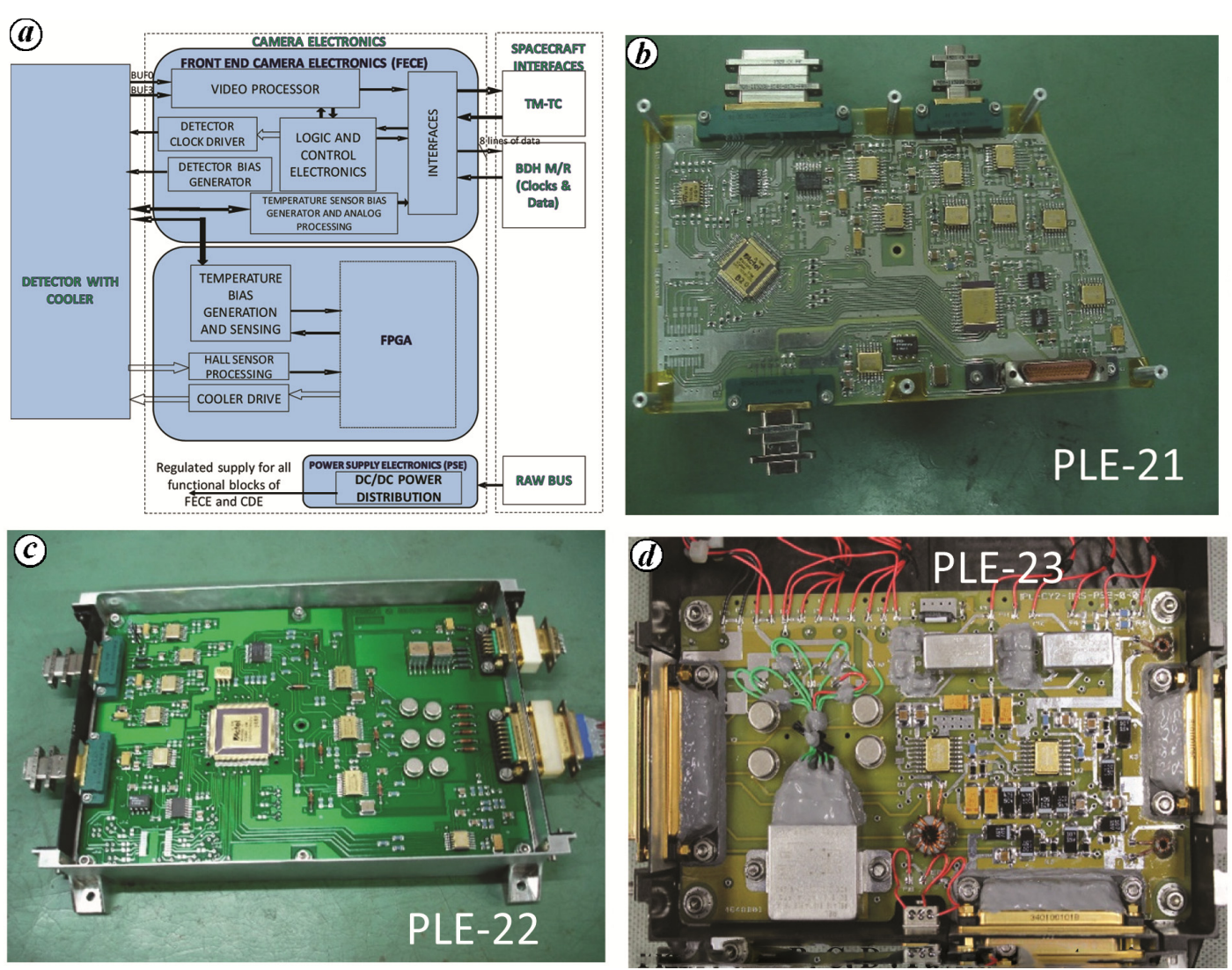

Figure 6. Payload electronics block diagram and units.

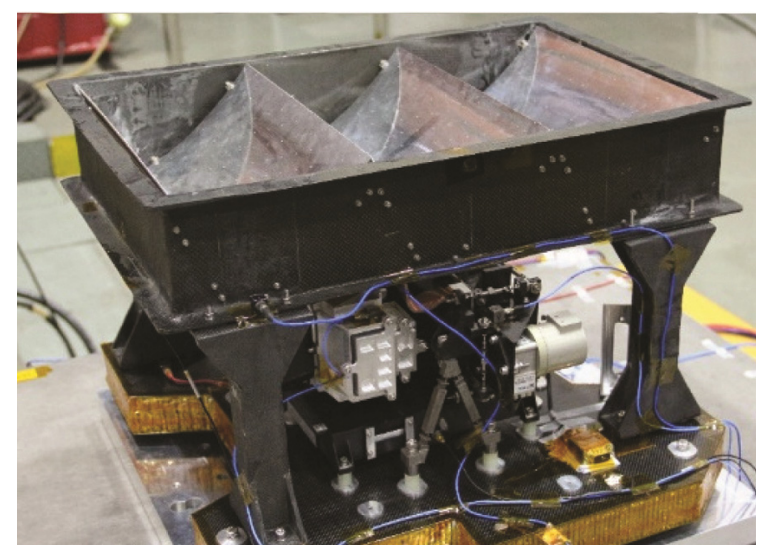

Figure 7. Mechanical system with passive radiator for cooling the electro-optical module.

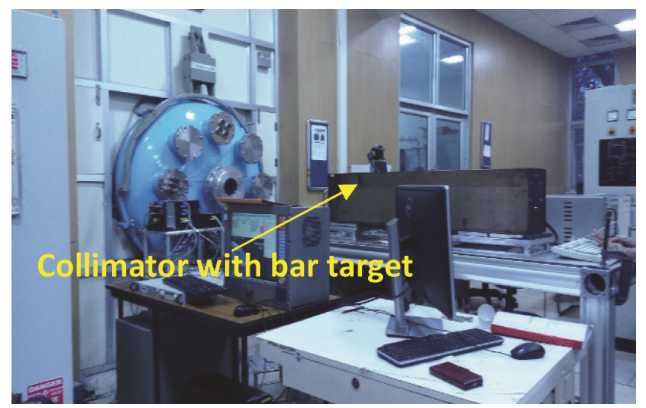

Figure 8. Square wave response measurement set-up with payload inside the thermo-vacuum chamber.
Table 5. Mechanical and thermal control system parameters

\begin{tabular}{lc}
\hline Parameter & Values \\
\hline Electro-optical module temperature $(\mathrm{K})$ & $\sim 225$ \\
Electronics temperature $\left({ }^{\circ} \mathrm{C}\right)$ & $0-40$ \\
FPA temperature $(\mathrm{K})$ & 90 \\
Size $\left(\mathrm{mm}^{3}\right)$ & $560 \times 330 \times 510$ \\
Mass $(\mathrm{kg})$ & 11.7 \\
\hline
\end{tabular}

Table 6. Spectral characterization parameters

\begin{tabular}{lc}
\hline Parameter & Values \\
\hline Spectral sampling (nm/pixel) & 16.85 \\
Spectral bandwidth, FWHM (nm) & $20-25$ \\
\hline
\end{tabular}

Table 7. Noise equivalent differential radiance performance

\begin{tabular}{lc}
\hline Parameter & Values $(0.8-5 \mu \mathrm{m})$ \\
\hline $\mathrm{NEdR}\left(\mathrm{mW} / \mathrm{cm}^{2} / \mathrm{sr} / \mu \mathrm{m}\right)$ & $0.001-0.005$ \\
\hline
\end{tabular}

(ii) optics is further thermally isolated from base plate using low thermal conductive material, and (iii) payload is radiatively isolated from the surrounding using a thermal shield. Multi-tier radiative isolation and multi-stage conductive cooling approach is selected for maintaining the EOM temperature. Figure 7 shows payload mechanical 


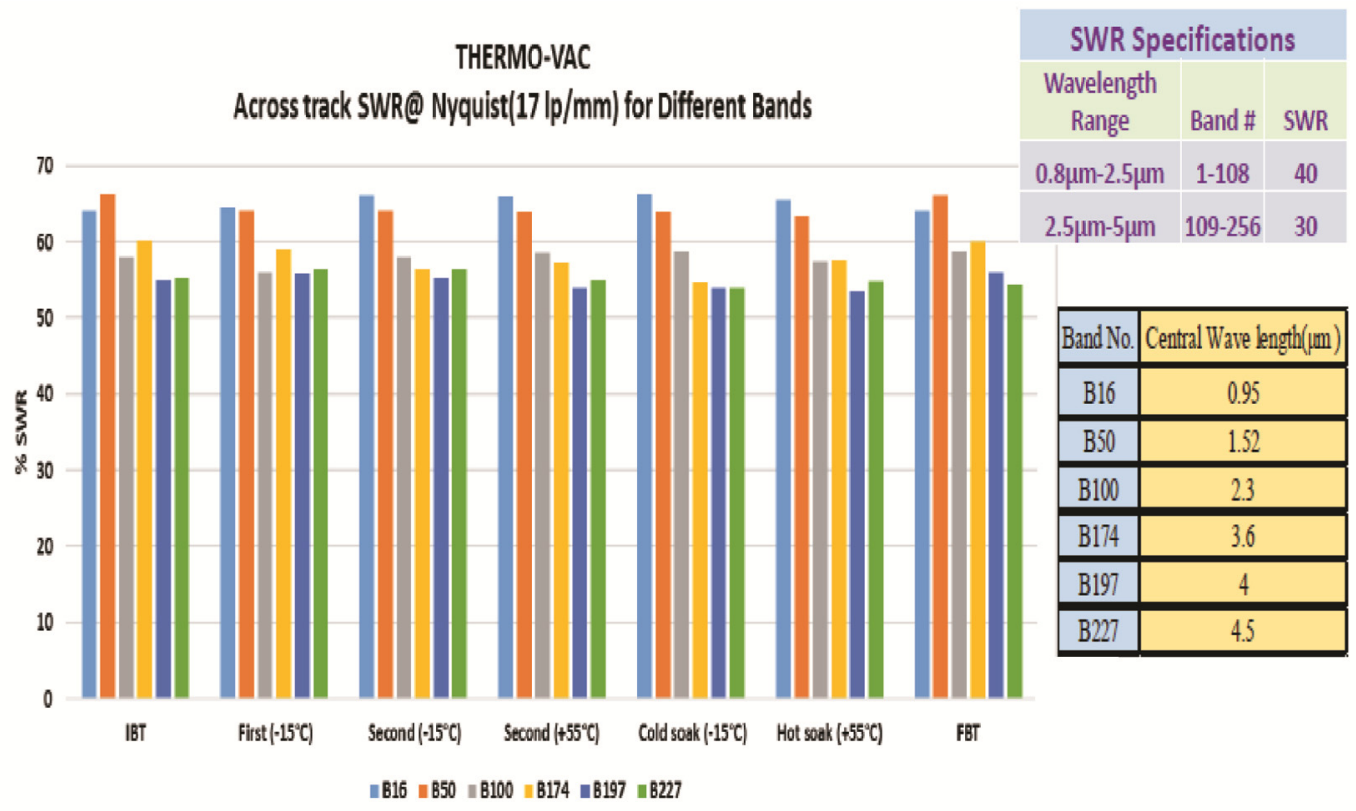

Figure 9. Measured system level SWR with payload inside the thermo-vacuum chamber at different test phase, different temperature and different bands.

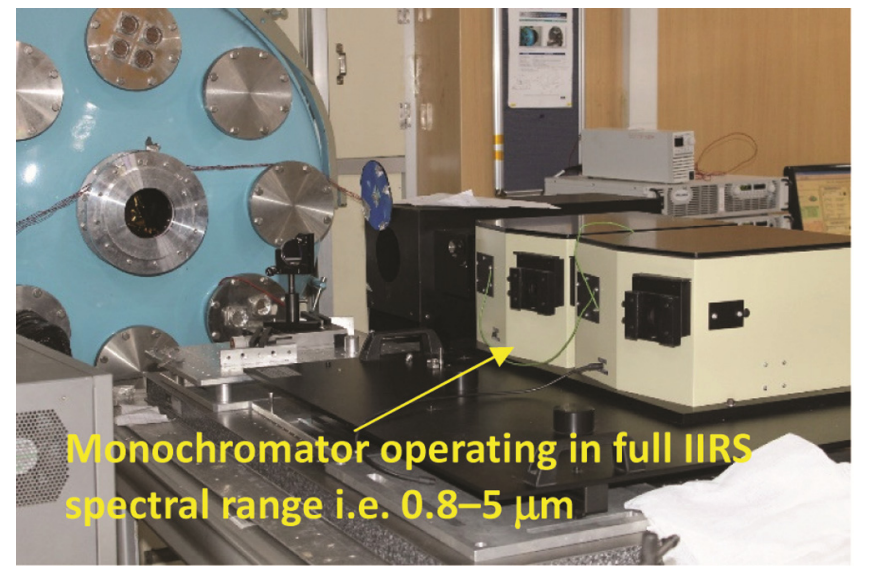

Figure 10. Spectral characterization set-up with payload inside the thermo-vacuum chamber.

structure with passive radiator. Table 5 provides mechanical and thermal control system parameters.

\section{Payload characterization}

\section{Optical characterization-SWR measurement}

System-level square wave response (SWR) is an indicator of image quality and purity of the spatial information among adjacent pixel locations. SWR measurement is carried out by keeping the payload in the thermo-vacuum chamber. SWR is measured at various test phases at different temperatures (test set-up is given in Figure 8). Figure 9 shows the SWR performance.

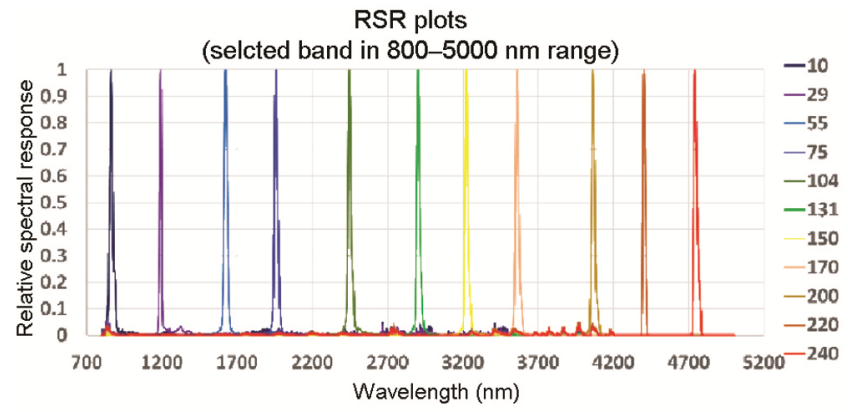

Figure 11. Measured system level relative spectral response (RSR) with payload inside the thermo-vacuum chamber.

\section{Spectral characterization}

Spectral characterization (test set-up is given in Figure 10) is carried out to measure spectral response (Figure 11; relative spectral response; RSR), central wavelengths and bandwidths of all bands ${ }^{6}$. Table 6 provides spectral characterization parameters.

\section{Radiometric characterization}

Radiometric characterization ${ }^{6}$ is carried out in two phases: (i) using integrating sphere (Figure $12 a$ ) for $0.8-2.5 \mu \mathrm{m}$ range and (ii) using blackbody (Figure $12 b$ ) for 2.5$5.0 \mu \mathrm{m}$ range.

Radiometric characterization is done to establish the relationship among the payload output counts to the input radiance, and to determine important parameters like response linearity, noise equivalent differential radiance 

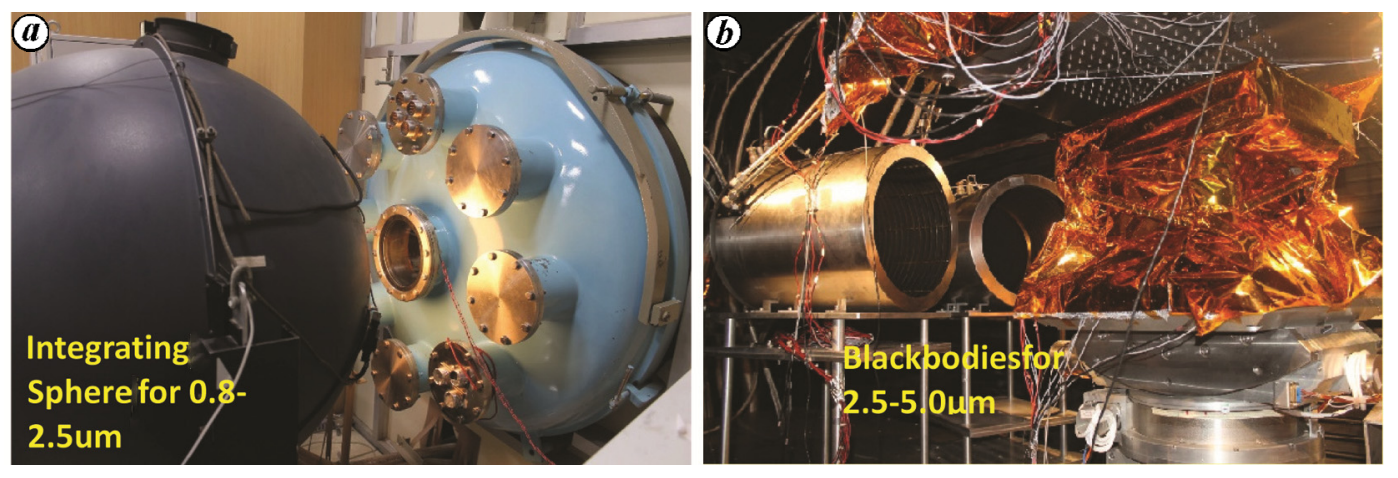

Figure 12. $\quad \boldsymbol{a}$, Radiometric characterization set-up (with integrating sphere as light source for $0.8-2.5 \mu \mathrm{m}$ spectral range) with payload inside the thermo-vacuum chamber. $\boldsymbol{b}$, Radiometric characterization set-up (with blackbodies as light source for $2.5-5.0 \mu \mathrm{m}$ spectral range) with IIRS payload inside the thermo-vacuum chamber.

(NEdR) and saturation radiance. Table 7 provides the NEdR performance of the IIRS payload.

\section{Data products}

The raw data collected from the IIRS payload of Chandrayaan-2 will be processed to correct different types of distortions present in them, before being archived. Data processing is planned according to three defined levels (0-2). Level-0 dataset consists of payload raw data (as it is collected from the payload), ancillary data (mainly SPICE kernels generated from the mission) and housekeeping data (health of the spacecraft). The data will be stored in a specific format in the database without any correction. Level-1 data are radiometrically corrected and geometrically tagged. Level-1 dataset includes processed radiance data along with Seleno tagging. Level-2 data will include radiometric, photometric, thermal and geometric corrections. Polar and regional mosaics are part special/higher-level products. All the level products will be disseminated in planetary data system (PDS-4) format, while special products will be in geo-tiff format.

\section{Summary}

The IIRS is a 250-band spectral range imaging spectrometer covering $0.8-5 \mu \mathrm{m}$. The instrument is designed, realized, space-qualified and ready to fly onboard Chandrayaan-2 spacecraft.

1. Banerjee, A. et al., SW-MW infrared spectrometer for lunar mission. In Proceedings of SPIE 9880, Multispectral, Hyperspectral, and Ultraspectral Remote Sensing Techniques and Applications VI, 98801F, 30 April 2016; doi:10.1117/12.2228225.

2. Kiran Kumar, A. S. et al., Hyper Spectral Imager for lunar mineral mapping in visible and near infrared band. Curr. Sci., 2009, 96(4), 496-499.
3. Pieters, C. M. et al., The Moon mineralogy mapper $\left(\mathrm{M}^{3}\right)$ on Chandrayaan-1. Curr. Sci., 2009, 96(4), 500-505.

4. Mall, U. et al., Near Infrared Spectrometer SIR-2 on Chandrayaan-1. Curr. Sci., 2009, 96(4), 506-511.

5. Pieters, C. M. et al., Character and spatial distribution of $\mathrm{OH} / \mathrm{H}_{2} \mathrm{O}$ on the surface of the Moon seen by $\mathrm{M}^{3}$ on Chandrayaan-1. Science, 2009, 326, 568-572.

6. Clark, R. N., Detection of adsorbed water and hydroxyl on the Moon. Science, 2009, 326, 562-564.

7. Sunshine, J. M. et al., Temporal and spatial variability of lunar hydration as observed by the deep impact spacecraft. Science, 2009, 326, 565-568.

8. Klima, R. et al., Remote detection of magmatic water in Bullialdus Crater on the Moon. Nature Geosci., 2013, 6, 737-741.

9. Bhattacharya, S. et al., Endogenic water on the Moon associated with non-mare silicic volcanism: implications for hydrated lunar interior. Curr. Sci., 2013, 105, 685-691.

10. Bhattacharya, S. et al., Detection of hydroxyl-bearing exposures of possible magmatic origin on the central peak of crater Theophilus using Chandrayaan-1 Moon Mineralogy Mapper $\left(\mathrm{M}^{3}\right)$ data. Icarus, 2015, 260, 167-173.

11. Li, S. et al., Water on the surface of the Moon as seen by the Moon Mineralogy Mapper: distribution, abundance and origins. Sci. Adv., 2017, 3, e1701471.

12. Milliken, R. E. and Li, S., Remote detection of widespread indigenous water in lunarpyroclastic deposits. Nature Geosci., 2017, 10, 561-565.

ACKNOWLEDGEMENTS. We acknowledge the contributions of all colleagues involved in the realization of the instrument. Contribution made by Dr Prakash Chauhan (Director, Indian Institute of Remote Sensing, Dehradun) is extremely valuable for the successful development of this instrument. We thank Division Heads, Group Directors (GDs) and Deputy Director (DD), Sensors Development Area (leading area for this payload development) for guidance and support. We also thank DDs, GDs and Heads of various areas of Space Applications Centre, ISRO for help and support and the Director, SAC for encouragement and support.

Received and accepted 27 August 2019

doi: $10.18520 / \mathrm{cs} / \mathrm{v} 118 / \mathrm{i} 3 / 368-375$ 